\title{
An assessment of skin temperature gradients in a tropical primate using infrared thermography and subcutaneous implants
}

\author{
Cynthia L. Thompson ${ }^{\mathrm{a}, *}$, Caleb Scheidel ${ }^{\mathrm{a}}$, Kenneth E. Glander ${ }^{\mathrm{b}}$, Susan H. Williams ${ }^{\mathrm{c}}$, \\ Christopher J. Vinyard ${ }^{\mathrm{d}}$ \\ a Department of Biomedical Sciences, Grand Valley State University, 1 N Campus Drive, Allendale, MI 49401, USA \\ b Department of Evolutionary Anthropology, Duke University, 104 Biological Sciences Building, Durham, NC 90383, USA \\ ${ }^{c}$ Department of Biomedical Sciences, Ohio University Heritage College of Osteopathic Medicine, 228 Irvine Hall, Athens, OH 45701, USA \\ d Department of Anatomy and Neurobiology, Northeast Ohio Medical University, 4209 State Route 44, Rootstown, OH 44272, USA
}

\section{A R T I C L E I N F O}

\section{Keywords:}

Subcutaneous temperature

Thermoregulation

Core-shell model

Heat loss

Howling monkey

Thermal windows

\begin{abstract}
A B S T R A C T
Infrared thermography has become a useful tool to assess surface temperatures of animals for thermoregulatory research. However, surface temperatures are an endpoint along the body's core-shell temperature gradient. Skin and fur are the peripheral tissues most exposed to ambient thermal conditions and are known to serve as thermosensors that initiate thermoregulatory responses. Yet relatively little is known about how surface temperatures of wild mammals measured by infrared thermography relate to subcutaneous temperatures. Moreover, this relationship may differ with the degree that fur covers the body. To assess the relationship between temperatures and temperature gradients in peripheral tissues between furred and bare areas, we collected data from wild mantled howling monkeys (Alouatta palliata) in Costa Rica. We used infrared thermography to measure surface temperatures of the furred dorsum and bare facial areas of the body, recorded concurrent subcutaneous temperatures in the dorsum, and measured ambient thermal conditions via a weather station. Temperature gradients through cutaneous tissues (subcutaneous-surface temperature) and surface temperature gradients (surface-ambient temperature) were calculated. Our results indicate that there are differences in temperatures and temperature gradients in furred versus bare areas of mantled howlers. Under natural thermal conditions experienced by wild animals, the bare facial areas were warmer than temperatures in the furred dorsum, and cutaneous temperature gradients in the face were more variable than the dorsum, consistent with these bare areas acting as thermal windows. Cutaneous temperature gradients in the dorsum were more closely linked to subcutaneous temperatures, while facial temperature gradients were more heavily influenced by ambient conditions. These findings indicate that despite the insulative properties of fur, for mantled howling monkeys surface temperatures of furred areas still demonstrate a relationship with subcutaneous temperatures. Given that most mammals possess dense fur, this provides insight for using infrared imaging in thermoregulatory studies of wild animals lacking bare skin.
\end{abstract}

\section{Introduction}

Body temperature is a fundamental aspect of animal thermoregulation that relates to a broad range of physiological and behavioral variables such as energetic expenditure, metabolic rate, patterns of food consumption, activity patterns, and social behavior (e.g., Agetsuma, 1995; Hanya, 2004; Kuraoka and Nakamura, 2011; Terrien et al., 2011; Nowack et al., 2013). Infrared thermal imaging has become an important technique in thermoregulatory research due to its ability to non-invasively assess surface temperatures of skin. This has opened new avenues of research, particularly in cases where invasive techniques of temperature measurement (e.g., implanted sensors, thermocouples, rectal or tympanic thermometers) are unfeasible or undesirable, such as when animal capture is difficult or can result in stress or injury (Wilson and McMahon, 2006; Cattet et al., 2008; Cunningham et al., 2015; McCafferty et al., 2015). Accordingly, infrared imaging has now been used in a variety of applications from research on thermoregulatory physiology to veterinary medicine (McCafferty, 2007; Tattersall and Cadena, 2010; Cilulko et al., 2013). While a large body of knowledge has been generated with this technique (reviewed in McCafferty, 2007; Tattersall and Cadena, 2010; McCafferty et al., 2011, 2015; Cilulko et al., 2013), there are

\footnotetext{
* Correspondence to: Grand Valley State University, Department of Biomedical Sciences, 1 N Campus Drive, Allendale, MI 49401, USA.

E-mail address: thompscy@gvsu.edu (C.L. Thompson).
} 
still gaps in our knowledge of how surface temperatures measured through thermal imaging relate to internal temperature, heat loss, and thermoregulation. These gaps are particularly evident in wild animals (but see Briscoe et al., 2014), especially given evidence that thermoregulatory patterns can differ between the wild and captivity (Geiser et al., 1990; Larcombe and Withers, 2007; Warnecke et al., 2007; Nord et al., 2009). Wild animals are subject to a range of thermal conditions which are not suitably replicated in captivity (Øritsland and Ronald, 1973). The non-invasiveness of infrared imaging makes it a particularly apt method to address questions of thermoregulation in animals' natural, ecologically- and evolutionarily-relevant environments.

While surface temperatures can provide a reliable proxy for core body temperatures in small $(<2 \mathrm{~kg}$ ) mammals (Audet and Thomas, 1996; Dausmann, 2005), these two temperature measurements are not always analogous for larger mammals (Jay et al., 2007; Larcombe, 2007; Sikoski et al., 2007; McCafferty et al., 2015, but see Giloh et al., 2012). This is generally attributed to the well accepted core-shell model, in which temperatures gradually change from the body's core out toward peripheral tissues (Aschoff and Wever, 1958; Romanovsky, 2007, 2014; Taylor et al., 2014). Peripheral areas of the body, in particular the skin, will be more heavily influenced by ambient thermal conditions, as this is where heat is exchanged with the environment. As such, warm ambient conditions can lead to elevated peripheral temperatures relative to core, while cool ambient conditions can lead to lower temperatures in peripheral tissues relative to core. Further, it is known that peripheral tissues act as thermosensors, with temperature changes at these locations triggering both autonomic and behavioral thermoregulatory responses (Roberts, 1988; Bratincsák and Palkovits, 2005; Romanovsky, 2014). These responses act to keep core body temperature stable. A range of thermoregulatory responses have been empirically linked to peripheral tissue temperatures, including vasomotion, shivering, and thyroid hormone variation, as well as perceived thermal environment (Cheng et al., 1995; Bulcao et al., 2000; Giloh et al., 2012). Peripheral tissue temperatures have thus been an informative tool for researchers investigating thermoregulation. As such, while peripheral tissue temperatures are not necessarily representative of core temperatures in larger mammals, these temperatures are independently informative and play a well-demonstrated role as a signal initiating thermoregulatory responses.

Several studies have looked at surface skin temperatures through infrared thermography (e.g., Mauck et al., 2003; Tattersall et al., 2009; Reichard et al., 2010; Weissenböck et al., 2010). Likewise, measuring core body temperatures is a hallmark of thermoregulatory studies (e.g., Togawa, 1985; Refinetti, 2010) and have been recorded for some wild mammals (e.g., Brain and Mitchell, 1999; Mzilikazi and Lovegrove, 2004; Mzilikazi et al., 2006; Lubbe et al., 2014). Yet relatively little work has examined subcutaneous temperatures in relation to this coreshell temperature gradient (Taylor et al., 2014; but see Sealander, 1953; Webb, 1992). Similarly, measurements of subcutaneous (or other internal) temperatures have only rarely been collected simultaneously with surface temperatures for wild animals (McCafferty, 2007; McCafferty et al., 2011, but see Dausmann, 2005). Since a primary advantage of infrared imaging is the ability to non-invasively gather surface temperatures on wild animals, understanding how temperature changes through the skin in a natural environment can provide insight into thermoregulatory strategies.

For mammals, infrared imaging of surface temperatures is complicated by the fact that the skin may contain areas both with and without fur, as well as substantial variation in hair density and length. Since fur can impact heat transfer both to and away from the body, this variation can influence heat loss (Scholander et al., 1950) and lead to the presence of thermal windows, which are areas of the body that are relatively more active in modulating heat transfer (Mauck et al., 2003; Tattersall et al., 2009; Reichard et al., 2010; Weissenböck et al., 2010). Body regions with little or no fur could be acting as thermal windows for mammals. While the surface temperature of skin has often been taken as indicative of vasomotion (e.g., Pergola et al., 1994; Cheng et al., 1995), furred skin lacks the same vasculature structure as bare skin and hence has different thermal profiles, with the temperature of bare skin varying more widely than furred skin (Krogstad et al., 1995; Romanovsky, 2014). Varying ambient temperatures will also influence surface temperatures, and the relationships between subcutaneous and surface temperatures in bare versus furred areas are not well established. Knowledge of subcutaneous measurements will allow us to quantify temperature changes through the cutaneous layer (skin and fur), and would supplement information on surface temperatures, which have more frequently been examined with infrared thermal imaging (e.g., Tattersall et al., 2009; McCafferty et al., 2011), albeit mostly for captive animals in laboratory settings (Jauchem et al., 2016).

We assessed the relationships between subcutaneous temperatures, surface temperatures from infrared images, and ambient thermal conditions for wild mantled howling monkeys (Alouatta palliata) in Costa Rica. Mantled howlers are relatively large-bodied (males: mean $=5.79 \mathrm{~kg}$; females: mean=4.73 kg: Glander, 2006) Neotropical primates that are densely furred across most of their body, but with less fur on their ventral surface and little to no fur on their face (similar to bare areas of human faces: Fig. 1a; Supplemental material S1). Howlers have no known traits indicative of thermal specialization (e.g., carotid rete, torpor, etc.) beyond generalized mammalian thermoregulatory mechanisms, but have been shown to experience both warm and cold thermal pressures in their natural environment (Thompson et al., 2014). We examined temperatures of peripheral tissues of the furred dorsum and bare facial areas of howling monkeys to characterize temperatures and temperature changes through peripheral tissues. Specifically, we assessed: 1) the influence of subcutaneous and ambient temperatures on surface temperatures in furred and bare areas, and 2) differences in cutaneous and surface temperature gradients across the furred dorsum and bare facial areas of the body. If the bare face serves as a thermal window facilitating heat loss, surface temperatures should be higher, with greater variation in temperature changes due to continuous vasomotion, although variation should decrease at temperature extremes (i.e., outside of the thermoneutral zone) as animals more consistently vasoconstrict to limit blood flow and heat loss at cooler temperatures, and vasodilate to promote heat loss under warm temperatures (Tattersall et al., 2009; Romanovsky, 2014). Lastly, we assessed 3) how peripheral temperature gradients (from the skin surface and through the cutaneous layer) are influenced by weather variables other than temperature (i.e., wind, humidity, solar radiation) which are known to impact thermoregulatory processes of free-ranging mammals (Hill et al., 2004). We addressed these questions with the ultimate aim of improving our interpretations of infrared thermography data from wild mammals.

\section{Methods}

\subsection{Data collection}

We collected data on mantled howling monkeys at La Pacifica, a private 1,980 ha ranch in Guanacaste Province, Costa Rica $\left(10^{\circ} 28^{\prime} \mathrm{N}\right.$, $85^{\circ} 07^{\prime} \mathrm{W}$ ). La Pacifica is a lowland tropical dry forest that is seasonally deciduous and mostly secondary growth. Mantled howlers at La Pacifica inhabit both riparian forests and seasonally dry, non-river forest patches (Glander and Nisbett, 1996). Based on weather monitoring from 1971 to 2006, daily temperatures during the dry season (November-April) range from 22.5 to $34.1{ }^{\circ} \mathrm{C}$ (mean $=28.1^{\circ} \mathrm{C}$ ) with $42 \%$ average relative humidity. Wet season (May-October) temperatures range from 21.8 to $33.8{ }^{\circ} \mathrm{C}$ (mean $=26.1{ }^{\circ} \mathrm{C}$ ) with $94 \%$ average relative humidity (in this study, data were only collected in the wet season). Mean annual precipitation is $1,368 \mathrm{~mm}$ with heavy rains occurring during the wet season and little precipitation during the dry season (Daubenmire, 1972; Glander, unpublished data). 

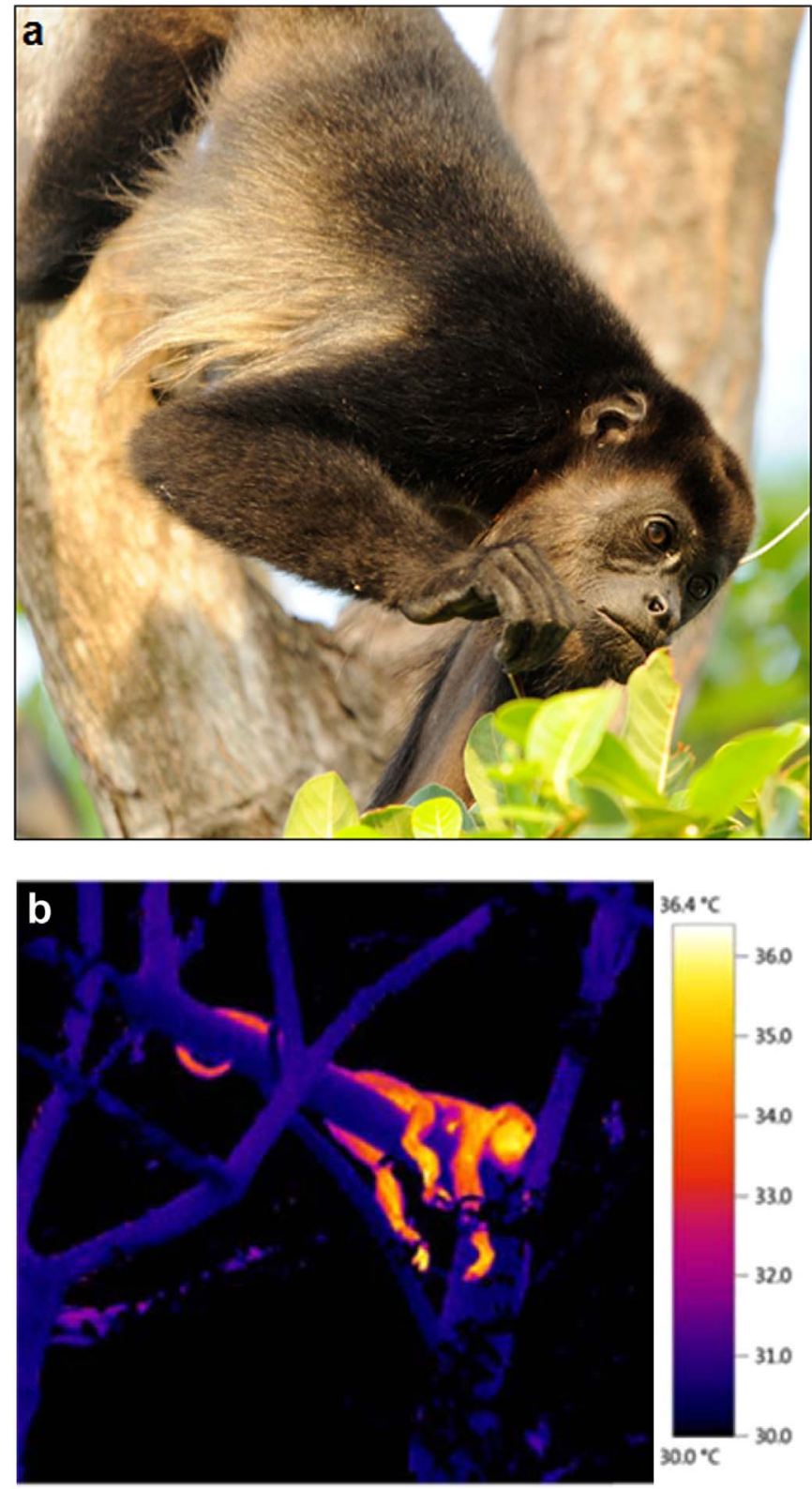

Fig. 1. Pictures of mantled howling monkeys (Alouatta palliata) showing the difference in fur coverage between face and body (a) and an infrared image (b).

Data were collected over a ten day period in the wet season (July) of 2014. Infrared thermal images (Fig. 1b) were taken at 10-minute intervals from 8:20 to 17:00 hrs, when animals met the following criteria for adequate imaging: 1) animals were clearly visible and not blocked from the camera by foliage, 2) surfaces for temperature readings were oriented directly toward the camera (to avoid effects of infrared thermography on curved surfaces: McCafferty, 2007), 3) the animal had to be sufficiently close ( $99.1 \%$ of images $<15 \mathrm{~m}$ ) to avoid underestimation of temperature due to the effects of increased distance and reduced pixel size (Faye et al., 2016), and 4) animals were not in direct sunlight, as solar radiation will influence temperature readings (McCafferty, 2007). The infrared camera (FLIR E60bx, FLIR Systems: see Supplemental material S2 for further details) had on-board inputs to account for humidity, ambient temperature, reflected apparent temperature, emissivity, and distance to the animal. Humidity and ambient temperature were measured immediately prior to imaging with a hand-held device (WS-HT12, Ambient Weather) at researcher height in the shade. These measurements were only input into the infrared camera, and not used for subsequent analyses. Reflected apparent temperature was measured following commonplace methods in thermography (Usamentiaga et al., 2014) by taking temperature readings of a crumpled and reflattened piece of aluminium foil within the image's field of view. Emissivity was set at 0.98 , the value for mammalian skin and fur (Steketee, 1973). Distance to the animal was estimated by observers and manually entered into the camera prior to imaging. We gathered 113 images from three animals (animal 1: $n=74$, 2: $n=35,3: n=4$ ). A one-way ANOVA did not reveal significant differences in surface temperatures among individuals $(F=0.87$, $P=0.42)$. A post-hoc power analysis revealed that our sample, with $56.0 \%$ power $(\beta=0.44)$, could detect large and medium, but not small, effect sizes (sensu Cohen, 1992). As such, we controlled for individual effects in subsequent analyses. From these images we measured temperature of the bare facial area $(n=32)$, the heavily-furred dorsum and lateral side of the trunk (hereafter, dorsum) $(n=86)$, and the less densely furred ventrum $(n=7)$. Since infrared cameras measure the surface temperatures of objects, measurements on furred areas represent temperatures on the surface of the fur. A previous study with captive primates did not find a significant influence of respiration on measurements of facial skin temperature taken with infrared imaging (Nakayama et al., 2005). Given the low sample size of ventrum measurements, these data were not formally analyzed. However, since the ventrum represents an intermediate condition between bare and densely furred areas (Supplemental material S1), we have provided summary statistics on this area for qualitative comparison.

Subcutaneous temperatures of animals were recorded by implanting a sterilized iButton (Maxim Integrated Products; $17 \mathrm{~mm} \times 6 \mathrm{~mm}$; $3.3 \mathrm{~g}$ ) between the scapulae while animals were under general anaesthesia (Lovegrove, 2009; Thompson et al., 2014). Loggers were calibrated by the manufacture as accurate to $\pm 0.5{ }^{\circ} \mathrm{C}$ and postproduction between-logger precision has been reported to be \pm $0.4^{\circ} \mathrm{C}$ (Johnson et al., 2005). Testing of our own loggers after data collection revealed a mean pairwise difference between loggers (placed in the same location) of $0.02{ }^{\circ} \mathrm{C}(\mathrm{SD}=0.68 ; n=129$ measurements from three loggers at ambient temperatures between $20.3-34.3^{\circ} \mathrm{C}$ ). Implanted loggers were placed deep to the hypodermis and superficial to muscle tissue. Subcutaneous temperature loggers were implanted during an initial capture and extracted upon recapture. We waited > $14 \mathrm{hr}$ postcapture to collect subcutaneous temperature data to avoid thermal effects of tiletamine-based anaesthesia on animals (Lopez et al., 2002). All animal procedures were approved by GVSU, NEOMED, and Duke University IACUCs.

To measure ambient thermal conditions, we deployed an on-site weather station (HOBO U30, Onset Computer Corporation) in a clearing adjacent to the home range of monitored animals (i.e., within $20 \mathrm{~m}$ ). This weather station measured ambient temperature, relative humidity, solar radiation, and wind speed. While the station also recorded precipitation, no thermal images overlapped with measurable precipitation. Data from subcutaneous iButtons and the weather station were taken at 10-minute intervals synchronized with thermal image collection. These three temperatures (surface, ambient, subcutaneous) collected at simultaneous 10-mintue intervals served as the units of analysis.

\subsection{Data analysis}

To assess the factors influencing surface temperatures, we conducted a multiple linear regression with subcutaneous and ambient temperatures as factors predicting surface temperatures, for both the dorsum and face separately. In addition to ambient temperature being a variable of interest, this variable also accounts for the effects of temperature change throughout and among days (e.g., mornings will be cooler) in other predictor variables. To assess the relative contribution of these variables to explaining surface temperatures, we calculated partial correlation coefficients for these regressions (Cohen et al., 2003). Individual effects were controlled through binary dummy 
variables (Jaccard and Turrisi, 2003). We also compared surface temperatures between the face and dorsum using a two-way ANOVA with body region as a fixed factor and animal as a random factor.

We calculated two measures of temperature change across the peripheral edge of the core-shell gradient: 1) the cutaneous temperature gradient, calculated as the difference between concurrent subcutaneous and surface temperatures, to serve as a measure of temperature change through the skin and fur (where fur was present), and 2) the surface temperature gradient, calculated as the difference between surface and ambient temperatures. While subcutaneous temperatures from the sensor placed between the scapulae will not identically reflect all subcutaneous temperatures in other portions of the dorsum, ventrum, and face, it does provide an initial, practical proxy of subcutaneous temperatures throughout the body. This placement also avoids complications with monkeys manually manipulating the implant site (which could impact healing) and the fact that iButtons (the smallest available automated temperature data logger: McCafferty et al., 2015) are unlikely to fit in the free portion of a mantled howler's face without impacting the orbit, nasal, or oral cavities. For reference, variation in subcutaneous temperatures across the human body has a standard deviation of $1^{\circ} \mathrm{C}$ (Webb, 1992). This error estimate, as well as the location of subcutaneous temperature measurement, should be considered when interpreting this study's results.

All following analyses were conducted separately for both cutaneous and surface temperature gradients. To explore differences between furred and bare areas, the difference in temperature gradients between the dorsum (furred) and face (bare) was tested using a twoway ANOVA with body region as a fixed factor and animal as a random factor. To compare variation in temperature gradients, we calculated the coefficients of variation (CV), adjusted for sample size: $\left(\frac{s}{\text { mean }} * 100\right) *\left(1+\frac{1}{n}\right)$, for both the face and dorsum. Differences in temperature gradient variation between the face and dorsum were also directly tested with a one-tailed Brown-Forsythe test for equality of variances. To assess how temperature gradients change with ambient temperature, we conducted linear regressions of temperature gradients on ambient temperature for the dorsum and face separately. Effects of animal were controlled through binary dummy variables (Jaccard and Turrisi, 2003). To assess whether variation in temperature gradients changed with ambient temperatures, we calculated the CV of temperature gradients at $1{ }^{\circ} \mathrm{C}$ intervals of ambient temperature (all animals pooled), then regressed these CVs on the ambient temperature for both the face and dorsum.

We used multiple linear regression and model selection criteria to assess the collective influence of all thermal variables measured by the weather station (i.e., ambient temperature, relative humidity, solar radiation, and wind speed) on surface and subcutaneous temperatures as well as temperature gradients. Model analyses were run separately for the face and dorsum. We used a combination of AIC, BIC, and $R^{2}$ values to select optimal models. Regression slopes are reported as standardized $\beta$. Except as indicated above, two-tailed $\alpha=0.05$. All variables in all models were entered simultaneously (i.e., not stepwise), so the order of reported variables did not impact results. All data were analyzed using SPSS.

\section{Results}

\subsection{Surface temperatures}

Surface temperatures of the furred dorsum were significantly and positively influenced by both ambient and subcutaneous temperatures (Table 1; Fig. 2a). Bare facial temperatures were significantly positively influenced by ambient temperatures, but not subcutaneous temperatures (Table 1; Fig. 2b). Ambient and subcutaneous temperatures explained nearly twice the amount of variation in surface temperatures in the dorsum as the face (Table 1). Since ambient and subcutaneous temperatures were positively correlated for both the dorsum $(r=0.64, P$ $<0.001)$ and face $(r=0.73, P<0.001)$ (Fig. 2a,b), the total variation in surface temperatures explained by the model $\left(R^{2}\right.$ : Table 1$)$ cannot be completely partitioned exclusively between these two predictor variables (i.e., the partial correlation coefficient: $\mathbf{p r}^{2}$ ) (Cohen et al., 2003). However, for the variance that can be independently attributed to a specific variable, both subcutaneous and ambient temperatures accounted for unique variance in dorsum surface temperatures $(18.2 \%$ and $29.1 \%$, respectively: Table 1) In comparison, subcutaneous temperature uniquely explained only $1.8 \%$ of variance in facial surface temperatures, compared to $15.1 \%$ by ambient temperatures (Table 1 ). Surface temperatures in the bare face were significantly warmer than the furred dorsum (Table 2). While variation in facial tempertures was lower than for the dorsum, the magnitude of this difference was small (1.5\%), particularly in comparison to variation in temperature gradients (Table 2).

\subsection{Temperature gradients}

Cutaneous temperature gradients were significantly higher in the furred dorsum than the bare face, with the ventrum showing intermediate cutaneous temperature gradients (Table 2). Surface temperature gradients were slightly higher for the face than the dorsum, but did not significantly differ (Table 2). Ventrum surface temperature gradients were relatively high, similar to the face. There was significantly greater variation in cutaneous temperature gradients in the face than dorsum (Table 2). Cutaneous temperature gradients were also high in the ventrum, but should be considered with caution given the low sample size. Variation in surface temperature gradients did not significantly differ between the face and dorsum (Table 2).

For the furred dorsum, cutaneous temperature gradients decreased as ambient temperatures increased $\left(\beta=-0.58, P<0.001, p^{2}=0.34\right)$, denoting that surface and subcutaneous temperatures became more similar at warmer ambient temperatures (Fig. 2c). The few ventrum temperatures measured also showed a negative relationship (Fig. 2c). However, there was not a significant relationship between cutaneous temperature gradients and ambient temperatures for the face $\left(\beta=-0.17, P=0.366, p r^{2}=0.03\right.$ ) (Fig. 2d). Surface temperature gradients decreased with increasing ambient temperatures for the dorsum $\left(\beta=-0.68, \quad P<0.001, \quad p r^{2}=0.46\right)$ and face $(\beta=-0.82, \quad P<0.001$, $p r^{2}=0.69$ ) (Fig. 2e,f).

Variation in cutaneous temperature gradients was related to ambient temperature for the furred dorsum, with the CV of cutaneous temperature gradients increasing at higher ambient temperatures ( $\beta=0.91, P=0.001, R^{2}=0.83$ ) (Fig. 3a). However, there was not a consistent relationship between the $\mathrm{CV}$ and ambient temperature for the bare face ( $\beta=0.18, P=0.71, R^{2}=0.03$ ) (Fig. 3a). Variation in surface temperature gradients increased with increasing ambient temperature for the dorsum $\left(\beta=0.88, P=0.002, R^{2}=0.78\right)$ and face $(\beta=0.92$, $P=0.004, R^{2}=0.84$ ) (Fig. $3 \mathrm{~b}$ ).

\subsection{Weather variables influencing temperature gradients}

The ranges of weather variables that monkeys experienced during infrared thermal imaging are reported in Table 3 . Weather variables other than temperature influenced surface temperatures, subcutaneous temperatures, and temperature gradients. For cutaneous temperature gradients in both the bare face and furred dorsum, the top regression models included some combination of ambient temperature, relative humidity, and solar radiation (Table 4). For the dorsum, ambient temperature had higher magnitude (more negative) regression coefficients $(\beta)$, indicating greater influence on temperature gradients, and statistically significant effects compared to other thermal variables (Table 4). However for the face, ambient temperature had lower regression coefficients relative to other variables and was only significant in one model (and absent in another). Instead, regression 
Table 1

Influence of subcutaneous and ambient temperatures on the surface temperature of the face and dorsum of mantled howling monkeys, controlling for animal effects.

\begin{tabular}{|c|c|c|c|c|c|c|c|}
\hline \multirow[t]{2}{*}{ Body part } & \multicolumn{3}{|c|}{ Subcutaneous temperature } & \multicolumn{3}{|c|}{ Ambient temperature } & \multirow[t]{2}{*}{ Total $R^{2}$} \\
\hline & $\beta$ & $P$ & $p r^{2}$ & $\beta$ & $P$ & $p r^{2}$ & \\
\hline Dorsum & 0.370 & $<0.001$ & 0.182 & 0.501 & $<0.001$ & 0.291 & 0.635 \\
\hline Face & 0.167 & 0.483 & 0.018 & 0.494 & 0.034 & 0.151 & 0.352 \\
\hline
\end{tabular}

$\beta$ : standardized regression coefficient.

$P$ : significance value, evaluated at $\alpha=0.05$. Significant values in bold italics.

$\mathrm{pr}^{2}$ : the partial correlation coefficient, or the percent of variance uniquely attributable to this variable (Cohen et al., 2003).

$R^{2}$ : variation explained by the full model.

Animal identity variables were all non-significant. Dorsum: $p r^{2}=0.017$; Face $p r^{2}=0.045$

For all tests and variables, variance inflation factors were $\leq 2.38$.
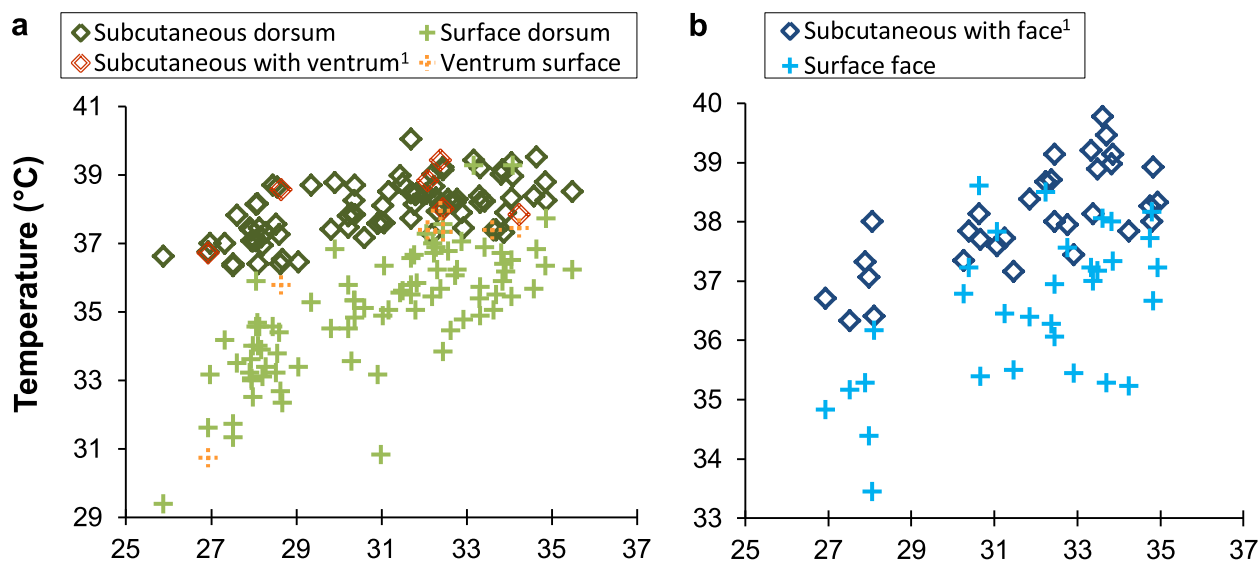

C

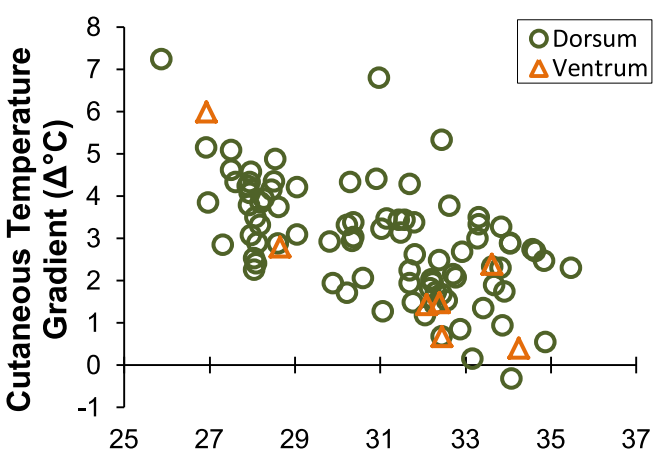

d
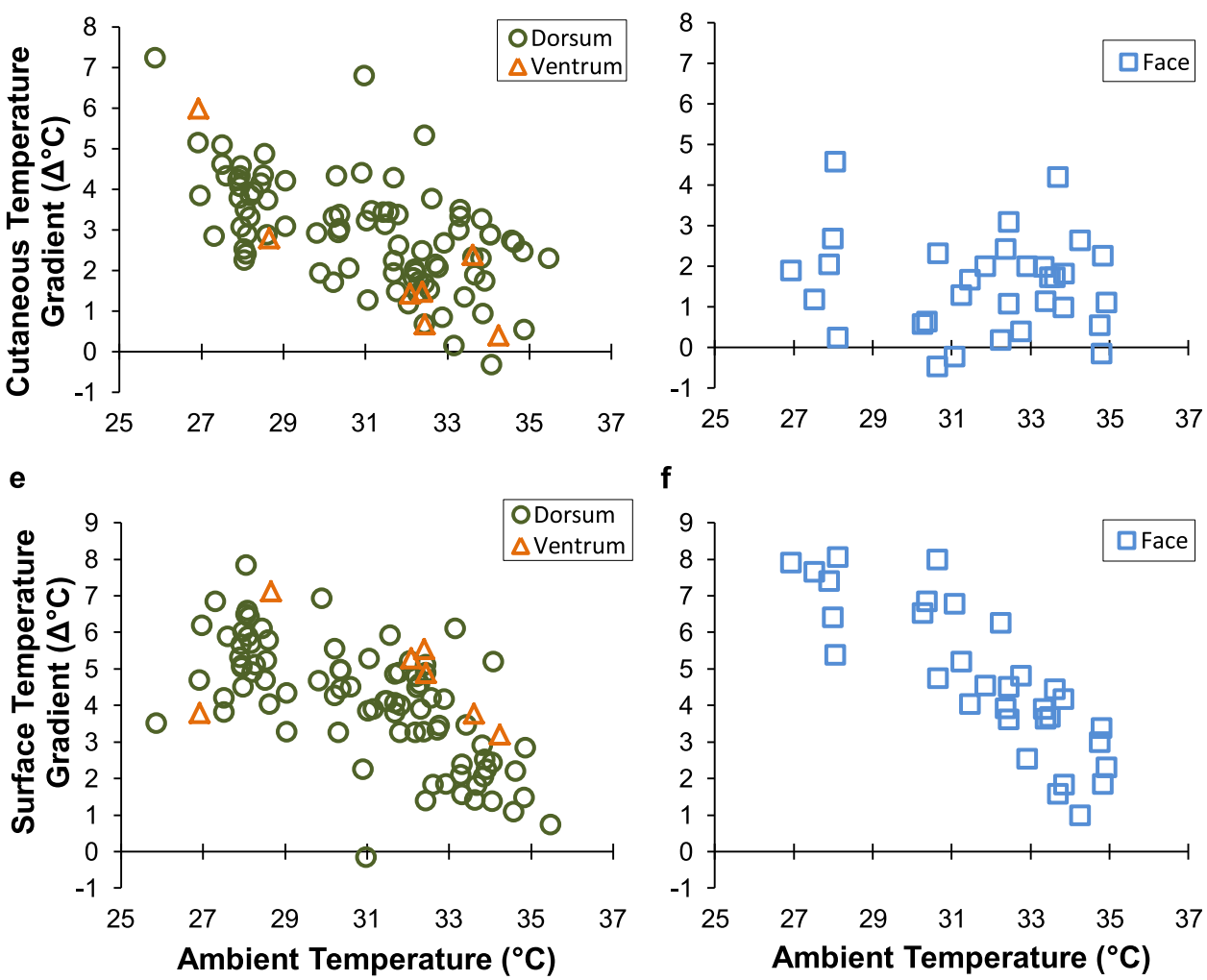

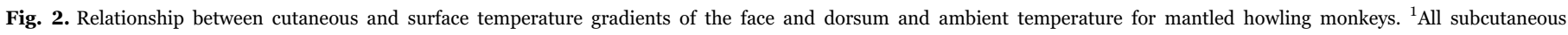

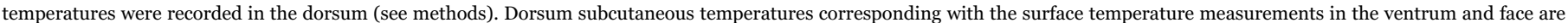

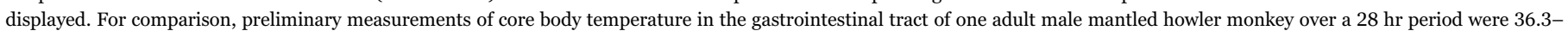
$38.4{ }^{\circ} \mathrm{C}$ (unpublished data). 
Table 2

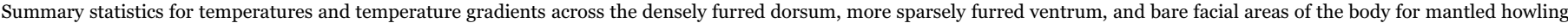
monkeys.

\begin{tabular}{|c|c|c|c|c|}
\hline Variable & Face $(n=32)$ & Dorsum $(n=86)$ & Face vs. dorsum comparison & Ventrum $^{\mathrm{a}}(n=7)$ \\
\hline Surface temperature $\left({ }^{\circ} \mathrm{C}:\right.$ mean, \pm SEM) & $36.54 \pm 0.22$ & $35.02 \pm 0.19$ & $F_{1,114}=18.22, P<0.001^{b}$ & $36.29 \pm 0.96$ \\
\hline Cutaneous temperature gradient $\left(\Delta^{\circ} \mathrm{C}:\right.$ mean, \pm SEM $)$ & $1.54 \pm 0.21$ & $2.93 \pm 0.14$ & $F_{1,114}=-25.09, P<0.001$ & $2.16 \pm 0.71$ \\
\hline Surface temperature gradient $\left(\Delta^{\circ} \mathrm{C}:\right.$ mean, \pm SEM $)$ & $4.67 \pm 0.36$ & $4.09 \pm 0.18$ & $F_{1,114}=2.31, P=0.131^{\mathrm{b}}$ & $4.79 \pm 0.51$ \\
\hline CV surface temperature $(\%)^{\mathrm{c}}$ & 3.6 & 5.1 & $F_{1,116}=26.51, P<0.001$ & 8.0 \\
\hline CV cutaneous temperature gradient $(\%)^{\mathrm{c}}$ & 78.8 & 46.3 & $F_{1,116}=30.24, P<0.001$ & 99.9 \\
\hline CV surface temperature gradient $(\%)^{\mathrm{c}}$ & 44.8 & 40.2 & $F_{1,116}=2.12, P=0.153^{\mathrm{d}}$ & 32.0 \\
\hline
\end{tabular}

a Due to small sample size, these data should be considered for qualitative comparison only.

b Two-way ANOVA controling for animal effects; animal effects were non-significant, but accounted for $1.0-2.8 \%$ of variation in temperature variables.

${ }^{c}$ Adjusted for sample size: $\mathrm{CV}=\left(\frac{\mathrm{s}}{\text { mean }} * 100\right) *\left(1+\frac{1}{\mathrm{n}}\right)$.

d Brown-Forsythe test for equality of variandes.

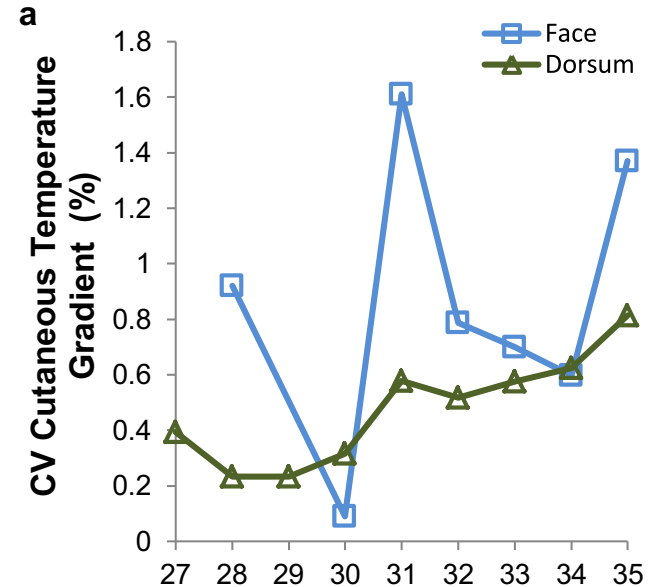

b

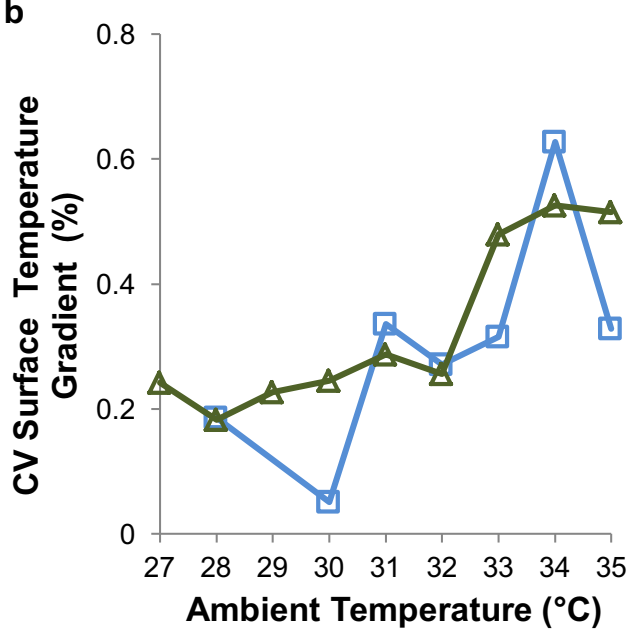

Fig. 3. Coefficients of variation (CV) in cutaneous (a) and surface (b) temperature gradients plotted against ambient temperature. Note difference in scale. Only one measurement of facial surface temperature was recorded at ambient temperatures of $27^{\circ} \mathrm{C}$ and hence the $\mathrm{CV}$ of temperature gradients could not be calculated at this value.

Table 3

Weather variables coinciding with infrared thermal imaging for mantled howling monkeys. Note that values correspond to weather at the specific time of sampling $(n=113)$, not continuous data from the entire study period.

\begin{tabular}{lccc}
\hline Variable & $\bar{x}$ & SD & Range \\
\hline Ambient temperature $\left({ }^{\circ} \mathrm{C}\right)$ & 31.21 & 2.42 & $25.89-35.50$ \\
Wind speed $(\mathrm{m} / \mathrm{s})$ & 0.34 & 0.26 & $0-1.01$ \\
Relative humidity $(\%)$ & 66.65 & 8.38 & $52.90-87.00$ \\
Solar radiation $\left(\mathrm{W} / \mathrm{m}^{2}\right)$ & 550.56 & 344.85 & $41.90-1276.90$ \\
\hline
\end{tabular}

coefficients, model inclusion, and significance cumulatively indicate that relative humidity played a more dominant role in facial cutaneous temperature gradients (Table 4). For cutaneous temperature gradients, regression models explained more variation for the dorsum than face (Table 4).

For surface temperature gradients, ambient temperature was included in the top regression models and showed a significant negative relationship in all models for both the face and dorsum. Wind speed and relative humidity were included in both face and dorsum models, but were not statistically significant. Ambient temperature and other weather variables explained substantially more variation in surface temperature gradients for the face than dorsum (Table 4).

Surface temperatures in the face and dorsum were positively influenced by ambient temperatures, with non-significant roles of wind speed and relative humidity in the model. In contrast, subcutaneous temperatures were better negatively predicted by relative humidity and solar radiation, with ambient temperature being included, but was not statistically significant, in only one of the models.

\section{Discussion}

\subsection{Thermal profiles of peripheral tissues}

We found significant differences in temperatures and cutaneous temperature gradients in furred compared to bare areas of mantled howlers' skin. Surface temperatures were more closely linked to subcutaneous temperatures in the furred dorsum than they were in the bare face. Subcutaneous temperatures had a larger magnitude effect on dorsum temperatures than the face (see $\beta$, Table 1 ) and explained more variance in dorsum surface temperatures than the face. Similarly, surface temperature gradients were far better explained by the suite of ambient thermal variables for the face than the dorsum (Table 4). This is likely mediated through relative humidity's role in vapour pressure and evaporative cooling as well as radiative heat transfer from the sun. This cumulatively suggests that for the range of ambient conditions measured in this study, furred dorsum surface temperatures of howlers are more closely linked to subcutaneous temperatures, while the bare face is more influenced by ambient, rather than internal, thermal conditions.

Our study also found that cutaneous temperature gradients were greater in the dorsum. This likely reflects the lower surface values of the distal fur compared to exposed facial skin and accordingly the insulation, reflection, and penetrance properties of fur. Overall, differences between the face and dorsum largely occurred in the cutaneous layer, rather than over surface temperature gradients (Table 2; Figs. 2c-f, 3). Given that many thermal imaging studies rely only on surface temperature and surface temperature gradients, this study indicates that peripheral tissue temperatures can provide added insight into temperature profiles, particularly across different areas of 
Table 4

Multiple linear regression models predicting peripheral tissue temperatures and temperature gradients in the face and dorsum from weather variables.

\begin{tabular}{|c|c|c|c|c|c|c|c|}
\hline & Ambient temperature $(\beta, P)$ & Wind speed $(\beta, P)$ & Relative humidity $(\beta, P)$ & Solar radiation $(\beta, P)$ & Adjusted $R^{2}$ & $\mathrm{AIC}$ & $\mathrm{BIC}$ \\
\hline \multicolumn{8}{|c|}{ Cutaneous temperature gradient } \\
\hline \multicolumn{8}{|l|}{ Dorsum } \\
\hline Model 1 & $-0.39,0.006$ & & & $-0.25,0.074$ & 0.346 & 16.94 & 24.30 \\
\hline 2 & $-1.01,<0.001$ & & $-0.46,0.096$ & & 0.342 & 17.37 & 24.73 \\
\hline 3 & $-0.74,0.031^{a}$ & & $-0.33,0.257^{\mathrm{a}}$ & $-0.19,0.194$ & 0.348 & 17.59 & $27.40^{\mathrm{b}}$ \\
\hline \multicolumn{8}{|l|}{ Face } \\
\hline Model 1 & $-0.69,0.183^{\mathrm{a}}$ & & $-1.01,0.021$ & $-0.39,0.163$ & 0.208 & 6.63 & 12.50 \\
\hline 2 & & & $-0.52,0.020$ & $-0.62,0.007$ & 0.185 & 6.69 & 11.09 \\
\hline 3 & $-1.15,0.008$ & & $-1.17,0.007$ & & 0.179 & 6.90 & 11.30 \\
\hline \multicolumn{8}{|c|}{ Surface temperature gradient } \\
\hline \multicolumn{8}{|c|}{ Dorsum } \\
\hline Model 1 & $-0.67,<0.001$ & & & & 0.436 & 36.09 & 41.00 \\
\hline 2 & $-0.70,<0.001$ & $0.09,0.327$ & & & 0.436 & 37.09 & 44.46 \\
\hline 3 & $-0.82,0.002$ & & $-0.16,0.518$ & & 0.433 & 37.66 & 45.02 \\
\hline \multicolumn{8}{|l|}{ Face } \\
\hline Model 1 & $-0.52,0.032$ & $0.16,0.173$ & $0.46,0.060$ & & 0.732 & 6.79 & 12.65 \\
\hline 2 & $-0.49,0.047$ & & $0.40,0.101$ & & 0.723 & 6.94 & 11.34 \\
\hline 3 & $-0.85,<0.001$ & & & & 0.706 & 7.96 & 10.89 \\
\hline \multicolumn{8}{|c|}{$\underline{\text { Surface temperature }}$} \\
\hline \multicolumn{8}{|l|}{ Dorsum } \\
\hline Model 1 & $0.74,<0.001$ & & & & 0.544 & 32.95 & 37.86 \\
\hline 2 & $0.71,<0.001$ & $0.07,0.380$ & & & 0.543 & 34.14 & 41.51 \\
\hline 3 & $0.61,0.009$ & & $-0.14,0.542$ & & 0.540 & 34.56 & 41.92 \\
\hline \multicolumn{8}{|l|}{ Face } \\
\hline Model 1 & $0.57,0.001$ & & & & $0.296^{\mathrm{c}}$ & 6.12 & 9.05 \\
\hline 2 & $1.02,0.010$ & & $0.49,0.190$ & & $0.314^{\mathrm{d}}$ & 6.19 & 10.59 \\
\hline 3 & $0.96,0.013$ & $0.24,0.195$ & $0.59,0.123$ & & $0.332^{\mathrm{e}}$ & 6.23 & $12.10^{\mathrm{e}}$ \\
\hline \multicolumn{8}{|c|}{ Subcutaneous temperature } \\
\hline Model 1 & & & $-0.85,<0.001$ & $-0.19,0.031$ & 0.532 & -126.10 & -117.92 \\
\hline 2 & & $0.05,0.493$ & $-0.83,<0.001$ & $-0.20,0.026$ & 0.530 & -124.59 & $-113.68^{f}$ \\
\hline 3 & $-0.27,0.142$ & & $-0.97,<0.001$ & & $0.521^{\mathrm{g}}$ & -123.52 & -113.68 \\
\hline
\end{tabular}

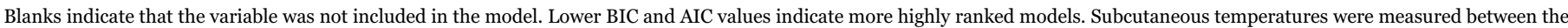
scapulae. Significant values are in bold italics.

${ }^{\text {a }}$ Variance inflation factor was $>10$, but in all cases < 15; see O'Brien (2007).

b This model ranked fourth using BIC, but was more suitable using both AIC and adjusted $R^{2}$ criteria.

${ }^{\mathrm{c}}$ Ranked $7^{\text {th }}$ using adjusted $R^{2}$ criteria, but $1^{\text {st }}$ using AIC and BIC criteria.

${ }^{\mathrm{d}}$ Ranked $3^{\text {rd }}$ using adjusted $R^{2}$ criteria, but $2^{\text {nd }}$ using AIC and BIC criteria.

${ }^{\text {e }}$ Ranked $2^{\text {nd }}$ using adjusted $R^{2}$ criteria and $3^{\text {rd }}$ using AIC, but $6^{\text {th }}$ under BIC criteria.

${ }^{\mathrm{f}}$ Ranked $4^{\text {th }}$ using BIC criteria, but $2^{\text {nd }}$ using AIC and adjusted $R^{2}$ criteria.

${ }^{\mathrm{g}}$ Ranked $4^{\text {th }}$ using adjusted $R^{2}$ criteria, but $3^{\text {rd }}$ using AIC and BIC criteria.

the body.

These results are also consistent with the idea that the face may play a relatively greater role in heat loss than other body areas. This is suggested by: 1) our finding that cutaneous temperature gradients in the face were more variable than the dorsum, and 2) variation in temperature gradients generally decreased at cooler ambient temperatures. However, this did not hold true at warmer temperatures, which may indicate these relatively cooler wet season data did not sample heat stress above animals' thermoneutral zone. Unfortunately, there are currently no published estimates of the thermoneutral zone of howlers. Lastly, 3) facial temperatures were warmer than dorsal temperatures. Alternately, the relatively greater impact of ambient conditions on the bare facial area could also explain warmer facial than dorsal temperatures, with warmer ambient temperatures driving warm temperatures of facial skin. However, our data do not support this alternate explanation, as ambient temperatures never exceeded surface temperatures of the face in this study (Fig. 2f). It is worth noting that this ten day study can only report on short term, rather than seasonal, temperature relationships of these body parts. However, previous research has found that daily variation, particularly cooler nighttime temperatures, are the most frequent thermal pressure faced by these tropical monkeys (Thompson et al., 2014; Thompson et al., in press).

Our results indicate that mantled howling monkeys display distinct temperature profiles across the body. While there are little comparative data on subcutaneous temperatures or heat loss for wild mammals, our results are consistent with human skin temperatures, which are also higher for the face than trunk (Taylor et al., 2014). This increased temperature has been attributed to high blood perfusion to the nearby brain (Romanovsky, 2014; Taylor et al., 2014). It is also worth noting that the face has unique functions beyond thermoregulation which may generate differences in temperature and temperature variations. Temperatures in the face have been linked to emotional state in humans (Clay-Warner and Robinson, 2015) and Old World monkeys (Kuraoka and Nakamura, 2011). This has not been rigorously examined for Neotropical monkeys such as howlers, but there is some evidence of similar temperature changes in the bare tails of rats exposed to fear stimuli (Vianna and Carrive, 2005). Such functions of the face and/or bare skin could contribute to the more variable temperature gradients in the cutaneous layer of the face found in this study. Beyond humans and mice, most identified thermal windows in mammals that possess some fur occur in areas with less dense or shorter fur, regardless of the exact location (e.g., faces for foxes: Klir and Heath, 1992; ventrum for camelids: Gerken, 2010; feet for otters: Kuhn and Meyer, 2009), although some mammals present clear exceptions with no evidence of such windows (Mongolian gerbils: Klir et al., 1990). While we did not measure subcutaneous temperatures directly in the face of mantled howlers, our findings that temperature patterns differed between the furred dorsum and bare 
face are congruent with research indicating that neural control of thermoregulatory responses, including vasomotion, differs between furred and bare skin (Saad et al., 2001; Kondo et al., 2003; Tanaka et al., 2007; Romanovsky, 2014). These body regions may also differ in the anatomical components of the cutaneous layer, such as thickness of subcutaneous fat, degree of vasculature, or prevalence of glands. While these anatomical features have not been examined for howlers, our data from wild animals support the notion that bare and furred areas have distinct thermoregulatory profiles.

\subsection{Methodological considerations for infrared imaging of wild mammals}

Based on our results, we can propose some guidance for future research. First, thermal imaging of furred areas can provide useful information, but are not an exact correlate of the underlying temperature of peripheral tissues. Despite that temperatures of bare skin are related to cutaneous blood flow (Love, 1980), surface temperatures of densely furred regions of howlers were more closely linked with subcutaneous temperatures than the bare regions of the face. Hence while the temperature of bare skin may intuitively seem like a better predictor of subcutaneous body temperature, this was not the case for wild howlers in our study. This is likely due to the relatively greater influence of ambient thermal variables on heat loss from the face's surface. Given these results for howlers, we would expect that surface temperatures of furred regions to be more similar to underlying tissues when ambient conditions (including temperature, solar radiation, humidity, etc.) are within animals' thermoneutral zone. It should also be noted that species differences in the thermal properties of fur could influence this relationship as well. This warrants further investigation, particularly given that the interaction between different fur properties (e.g., length, density, reflectance) can have a potentially multi-faceted relationship with the degree of insulation provided (Šumbera et al., 2007; Dawson et al., 2014). For instance, longer fur could provide higher insulation than shorter fur, but fur of equal lengths with higher or lower density would provide differing levels of insulation. This variation indicates that researchers should ensure the location of surface temperature measurements is consistent in order to ensure data reliability. Since a large number of mammalian species are completely covered in fur with no bare areas exposed for imaging, a demonstrated relationship (even if not a perfect correlation) between surface and subcutaneous temperature for furred skin provides a tool for advancing non-invasive studies of thermoregulation of wild mammals.

Second, despite the relationship between subcutaneous and surface temperatures, surface temperatures should not be viewed as an exact analog of body temperatures, even for peripheral tissues (e.g., Newsom et al., 2004; Sikoski et al., 2007). While surface temperatures are related to subcutaneous temperatures, particularly for furred areas, our study still showed clear temperature changes through the cutaneous layer, suggesting that heat loss in this region is not negligible, particularly in colder conditions (Fig. 2c-f). Our data indicate this discrepancy may be due to increased heat loss over exposed body parts, as well as the greater influence of ambient thermal conditions on surface temperatures. Studies in birds using non-infrared imaging methods similarly report significant effects of ambient thermal conditions on skin temperatures (Øritsland and Ronald, 1973; Nord et al., 2016).

Finally, taking ambient temperature into account with thermal images can improve reliability of infrared thermal images. For both bare and furred areas of howlers, adding thermal environment to predictive models increased their explanatory value. Ambient temperatures have been frequently considered in thermal imaging studies and this study demonstrates that they had a large influence on surface temperatures in howlers. However our data, from just ten days in the wet season, found that weather variables beyond temperature (wind, humidity, solar radiation) also impact temperatures gained from thermal imaging. Presumably future studies of longer duration would sample greater variation in weather conditions, which should be accounted for in analyses of surface temperatures.

\subsection{Conclusions}

Infrared imaging's non-invasiveness makes it an attractive tool for studying wild animals, although most wild studies have focused on generalized uses (e.g., animal detection, pathology, pregnancy detection) rather than thermoregulatory research (Cilulko et al., 2013). Here, we demonstrate that furred regions of mammals can contribute important information on the temperatures of peripheral tissues, and that differences in fur coverage and ambient thermal conditions can differentially influence temperature change through these tissues. Our results indicate that infrared thermal imaging can be useful for thermoregulatory studies of wild mammals.

\section{Acknowledgements}

We thank La Pacifica, The Organization for Tropical Studies, and Costa Rica's Ministerio de Ambiente y Energia. Field assistance was given by D. Mijatovic and J. Sidote.

\section{Appendix A. Supplementary material}

Supplementary data associated with this article can be found in the online version at doi:10.1016/j.jtherbio.2016.11.005.

\section{References}

Agetsuma, N., 1995. Dietary selection by yakushima macaques (Macaca fuscata yakui): The influence of food availability and temperature. Int. J. Primatol. 15, 611-627.

Aschoff, J., Wever, R., 1958. Kern und schale im waermehaushalt des menschen. Naturwissenschaften 45, 477-485.

Audet, D., Thomas, D.W., 1996. Evaluation of the accuracy of body temperature measurement using external radio transmitters. Can. J. Zool. 74, 1778-1781.

Brain, C., Mitchell, D., 1999. Body temperature changes in free-ranging baboons (Papio hamadryas ursinus) in the Namib desert, Namibia. Int. J. Primatol. 20, 585-598.

Bratincsák, A., Palkovits, M., 2005. Evidence that peripheral rather than intracranial thermal signals induce thermoregulation. Neuroscience 135, 525-532.

Briscoe, N.J., Handasyde, K.A., Griffiths, S.R., Porter, W.P., Krockenberger, A., Kearney, M.R., 2014. Tree-hugging koalas demonstrate a novel thermoregulatory mechanism for arboreal mammals. Biol. Lett. 10, 20140235.

Bulcao, C.F., Frank, S.M., Raja, S.N., Tran, K.M., Goldstein, D.S., 2000. Relative contribution of core and skin temperatures to thermal comfort in humans. J. Therm. Biol. 25, 147-150

Cattet, M., Boulanger, J., Stenhouse, G., Powell, R.A., Reynolds-Hogland, M.J., 2008. An evaluation of long-term capture effects in ursids: Implications for wildlife welfare and research. J. Mammal. 89, 973-990.

Cheng, C., Matsukawa, T., Sessler, D.I., Makoto, O., Kurz, A., Merrifield, B., Lin, H., Olofsson, P., 1995. Increasing mean skin temperature linearly reduces the coretemperature thresholds for vasoconstriction and shivering in humans. Anesthesiology 82, 1160-1168.

Cilulko, J., Janiszewski, P., Bogdaszewski, M., Szczygielska, E., 2013. Infrared thermal imaging in studies of wild animals. Eur. J. Wildlife Res. 59, 17-23.

Clay-Warner, J., Robinson, D.T., 2015. Infrared thermography as a measure of emotion response. Emot. Rev. 7, 157-162.

Cohen, J., 1992. Statistical power analysis. Curr. Dir. Psychol. 1, 98-101.

Cohen, J., Cohen, P., West, S.G., Aiken, L.S., 2003. Applied Multiple Regression/ Correlation Analysis for the Behavioral Sciences 3rd ed.. Lawrence Erlbaum Associates, Inc., Mahwah, New Jersey.

Cunningham, E.P., Unwin, S., Setchell, J.M., 2015. Darting primates in the field: a review of reporting trends and a survey of practices and their effect on the primates involved. Int. J. Primatol. 36, 911-932.

Daubenmire, R., 1972. Phenology and other characteristics of tropical semi-deciduous forest in north-western Costa Rica. J. Ecol. 60, 147-170.

Dausmann, K.H., 2005. Measuring body temperature in the field - evaluation of external vs. implanted transmitters in a small mammal. J. Therm. Biol. 30, 195-202.

Dawson, T.J., Webster, K.N., Maloney, S.K., 2014. The fur of mammals in exposed environments; do crypsis and thermal needs necessarily conflict? The polar bear and marsupial koala compared. J. Comp. Phys. B 184, 273-284.

Faye, E., Dangles, O., Pincebourde, S., 2016. Distance makes the difference in thermography for ecological studies. J. Therm. Biol. 56, 1-9.

Geiser, F., Sink, H., Stahl, B., Mansergh, I., Broome, L., 1990. Differences in the physiological-response to cold in wild and laboratory-bred mountain pygmy 
possums, Burramys parvus (Marsupialia). Wildlife Res. 17, 535-539.

Gerken, M., 2010. Relationships between integumental characteristics and thermoregulation in South American camelids. Animal 4, 1451-1459.

Giloh, M., Shinder, D., Yahav, S., 2012. Skin surface temperature of broiler chickens is correlated to body core temperature and is indicative of their thermoregulatory status. Poult. Sci. 95, 175-188.

Glander, K.E., 2006. Average body weight for mantled howling monkeys (Alouatto palliata): An assessment of average values and variability. In: Estrada, A.E., Garber, P.A., Pavelka, M.S., Luecke, L.L. (Eds.), New Perspectives in the Study of Mesoamerican Primates. Springer, New York, 247-263.

Glander, K.E., Nisbett, R.A., 1996. Community structure and species diversity in tropical forest associations at Hacienda La Pacifica in Guanacaste Province, Costa Rica. Brenesia 45-46, 113-142.

Hanya, G., 2004. Seasonal variations in the activity budget of Japanese macaques in the coniferous forest of Yakushima: effects of food and temperature. Am. J. Primatol. 63, $165-177$.

Hill, R., Weingrill, T., Barrett, L., Henzi, S.P., 2004. Indices of environmental temperatures for primates in open habitats. Primates 45, 7-13.

Jaccard, J., Turrisi, R., 2003. Interaction Effects in Multiple Regression, second ed. Sage Publications.

Jauchem, J.R., Ryan, K.L., Walters, T.J., 2016. Pathophysiological alterations induced by sustained 35-GHz radio-frequency energy heating. J. Basic Clin. Physiol. Pharmacol. $27,79-89$.

Jay, O., Reardon, F.D., Webb, P., Ducharme, M.B., Ramsay, T., Nettlefold, L., Kenny, G.P., 2007. Estimating changes in mean body temperature for humans during exercise using core and skin temperatures is inaccurate even with a correction factor. J. Appl. Physiol. 103, 443-451.

Johnson, A.N., Boer, B.R., Woessner, W.W., Stanford, J.A., Poole, G.C., Thomas, S.A., O'Daniel, S.J., 2005. Evaluation of an inexpensive small-diameter temperature logger for documenting ground water-river interactions. Ground Water Monit. Remediat. 25, 68-74.

Klir, J.J., Heath, J.E., 1992. An infrared thermographic study of surface temperature in relation to external thermal stress in three species of foxes: The red fox (Vulpes vulpes), arctic fox (Alopex lagopus), and kit fox (Vulpes macrotis). Physiol. Zool. 65, 1011-1021.

Klir, J.J., Heath, J.E., Bennani, N., 1990. An infrared thermographic study of surface temperature in relation to external thermal stress in the Mongolian gerbil, Meriones unguiculatus. Comp. Biochem. Physiol. A 96, 141-146.

Kondo, N., Yanagimoto, S., Nishiyasu, T., Crandall, C.G., 2003. Effects of muscle metaboreceptor stimulation on cutaneous blood flow from glabrous and nonglabrous skin in mildly heated humans. J. Appl. Physiol. 94, 1829-1835.

Krogstad, A., Elam, M., Karlsson, T., Wallin, B.G., 1995. Arteriovenous anastomoses and the thermoregulatory shift between cutaneous vasoconstrictor and vasodilator reflexes. J. Auton. Nerv. Syst. 53, 215-222.

Kuhn, R.A., Meyer, W., 2009. Infrared thermography of the body surface in the Eurasian otter Lutra lutra and the giant otter Pteronura brasiliensis. Aquat. Biol 6, 143-152.

Kuraoka, K., Nakamura, K., 2011. The use of nasal skin temperature measurements in studying emotion in macaque monkeys. Physiol. Behav. 102, 347-355.

Larcombe, A., 2007. Measurement of southern brown bandicoot (Isoodon obesulus) body temperature using internal and external telemeters. J. R. Soc. West. Aust 90 , $161-163$.

Larcombe, A.N., Withers, P.C., 2007. Effects of long-term captivity on thermoregulation, metabolism and ventilation of the southern brown bandicoot (Marsupialia: Peramelidae). J. Comp. Physiol. B 177, 229-236.

Lopez, K.R., Gibbs, P.H., Reed, D.S., 2002. A comparison of body temperature changes due to the administration of ketamine-acepromazine and tiletamine-zolazepam anesthetics in cynomolgus macaques. JAALAS 41, 47-50.

Love, T.J., 1980. Thermography as an indicator of blood perfusion. Ann. NY Acad. Sci $335,429-437$

Lovegrove, B., 2009. Modification and miniaturization of Thermochron iButtons for surgical implantation into small animals. J. Comp. Physiol. B 179, 451-458.

Lubbe, A., Hetem, R.S., McFarland, R., Barrett, L., Henzi, P., Mitchell, D., Meyer, L.C.R., Maloney, S.K., Fuller, A., 2014. Thermoregulatory plasticity in free-ranging vervet monkeys, Chlorocebus pygerythrus. J. Comp. Physiol. B 184, 799-809.

Mauck, B., Bilgmann, K., Jones, D.D., Eysel, U., Dehnhardt, G., 2003. Thermal windows on the trunk of hauled-out seals: Hot spots for thermoregulatory evaporation? J. Exp. Biol 206, 1727-1738.

McCafferty, D., Gilbert, C., Paterson, W., Pomeroy, P., Thompson, D., Currie, J., Ancel, A., 2011. Estimating metabolic heat loss in birds and mammals by combining infrared thermography with biophysical modeling. Comp. Biochem. Physiol. A 158, $337-345$.

McCafferty, D.J., 2007. The value of infrared thermography for research on mammals: Previous applications and future directions. Mamm. Rev. 37, 207-223.

McCafferty, D.J., Gallon, S., Nord, A., 2015. Challenges of measuring body temperatures of free-ranging birds and mammals. Anim. Biotelemetry 3, 1-10.

Mzilikazi, N., Lovegrove, B.G., 2004. Daily torpor in free-ranging rock elephant shrews, Elephantulus myurus: A year-long study. Physiol. Biochem. Zool. 77, 285-296.

Mzilikazi, N., Masters, J.C., Lovegrove, B.G., 2006. Lack of torpor in free-ranging southern lesser galagos, Galago moholi: Ecological and physiological considerations. Folia Primatol. 77, 465-476.
Nakayama, K., Goto, S., Kuraoka, K., Nakamura, K., 2005. Decrease in nasal temperature of rhesus monkeys (Macaca mulatta) in negative emotional state. Physiol. Behav. 84, 783-790.

Newsom, D.M., Bolgos, G.L., Colby, L., Nemzek, J.A., 2004. Comparison of body surface temperature measurement and conventional methods for measuring temperature in the mouse. JAALAS $\mathbf{4 3}, 13-18$.

Nord, A., Nilsson, J.F., Sandell, M.I., Nilsson, J., 2009. Patterns and dynamics of restphase hypothermia in wild and captive blue tits during winter. J. Comp. Physiol. B 179, 737-745

Nord, A., Lehmann, M., MacLeod, R., McCafferty, D.J., Nager, R.G., Nilsson, J., Helm, B., 2016. Evaluation of two methods for minimally invasive peripheral body temperature measurement in birds. J. Avian Biol. 47, 417-427.

Nowack, J., Wippich, M., Mzilikazi, N., Dausmann, K.H., 2013. Surviving the cold, dry period in Africa: Behavioral adjustments as an alternative to heterothermy in the African lesser bushbaby (Galago moholi). Int. J. Primatol. 34, 49-64.

O’Brien, R.M., 2007. A caution regarding rules of thumb for variance inflation factors. Qual. Quan. 41 (5), 673-690.

Øritsland, N., Ronald, K., 1973. Effects of solar radiation and windchill on skin temperature of the harp seal, Pagophilus groenlandicus (Erxleben, 1777). Comp. Biochem. Physiol. A 44, 519-525.

Pergola, P.E., Kellogg, D.L., Johnson, J.M., Kosiba, W.A., 1994. Reflex control of active cutaneous vasodilation by skin temperature in humans. Am. J. Physiol. 266 , H1979-H1984.

Refinetti, R., 2010. The circadian rhythm of body temperature. Front. Biosci. 15, 564-594.

Reichard, J.D., Prajapati, S.I., Austad, S.N., Keller, C., Kunz, T.H., 2010. Thermal windows on Brazilian free-tailed bats facilitate thermoregulation during prolonged flight. Integr. Comp. Biol. 50, 358-370.

Roberts, W.W., 1988. Differential thermosensor control of thermoregulatory grooming, locomotion, and relaxed postural extension. Ann. N.Y. Acad. Sci 525, 363-374.

Romanovsky, A.A., 2007. Thermoregulation: some concepts have changed. Functional architecture of the thermoregulatory system. Am. J. Physiol-Reg. I 292, R37-R46.

Romanovsky, A.A., 2014. Skin temperature: Its role in thermoregulation. Acta Physiol. 210, 498-507.

Saad, A.R., Stephens, D.P., Bennett, L.A., Charkoudian, N., Kosiba, W.A., Johnson, J.M., 2001. Influence of isometric exercise on blood flow and sweating in glabrous and nonglabrous human skin. J. Appl. Physiol. 91, 2487-2492.

Scholander, P.F., Walters, V., Hock, R., Irving, L., 1950. Body insulation of some arctic and tropical mammals and birds. Biol. Bull. 99, 225-236.

Sealander, J.A., 1953. Body temperatures of white-footed mice in relation to environmental temperature and heat and cold stress. Biol. Bull. 104, 87-99.

Sikoski, P., Banks, M., Gould, R., Young, R., Wallace, J., Nader, M., 2007. Comparison of rectal and infrared thermometry for obtaining body temperature in cynomolgus macaques (Macaca fascicularis). J. Med. Primatol. 36, 381-384.

Steketee, J., 1973. Spectral emissivity of skin and pericardium. Phys. Med. Biol. 18, 686.

Sumbera, R., Zelová, J., Kunc, P., Knížková, I., Burda, H., 2007. Patterns of surface temperatures in two mole-rats (Bathyergidae) with different social systems as revealed by IR-thermography. Physiol. Behav. 92, 526-532.

Tanaka, M., Ootsuka, Y., McKinley, M.J., McAllen, R.M., 2007. Independent vasomotor control of rat tail and proximal hairy skin. J. Physiol 582, 421-433.

Tattersall, G., Cadena, V., 2010. Insights into animal temperature adaptations revealed through thermal imaging. Imaging Sci. J. 58, 261-268.

Tattersall, G.J., Andrade, D.V., Abe, A.S., 2009. Heat exchange from the toucan bill reveals a controllable vascular thermal radiator. Science 325, 468-470.

Taylor, N.A., Tipton, M.J., Kenny, G.P., 2014. Considerations for the measurement of core, skin and mean body temperatures. J. Therm. Biol. 46, 72-101.

Terrien, J., Perret, M., Aujard, F., 2011. Behavioral thermoregulation in mammals: a review. Front. Biosci. 16, 1428-1444.

Thompson, C.L., Williams, S.H., Glander, K.E., Vinyard, C.J., in press. Measuring microhabitat temperature in arboreal primates: a comparison of on-animal and stationary approaches Int. J. Primatol.

Thompson, C.L., Williams, S.H., Glander, K.E., Teaford, M.F., Vinyard, C.J., 2014. Body temperature and thermal environment in a generalized arboreal anthropoid, wild mantled howling monkeys (Alouatta palliata). Am. J. Phys. Anthropol. 154, 1-10.

Togawa, T., 1985. Body temperature measurement. Clin. Phys. Physiol. Meas. 6, 83-108.

Usamentiaga, R., Venegas, P., Guerediaga, J., Vega, L., Molleda, J., Bulnes, F.G., 2014 Infrared thermography for temperature measurement and non-destructive testing. Sensors 14, 12305-12348.

Vianna, D.M., Carrive, P., 2005. Changes in cutaneous and body temperature during and after conditioned fear to context in the rat. Eur. J. Neurosci. 21, 2505-2512.

Warnecke, L., Withers, P.C., Schleucher, E., Maloney, S.K., 2007. Body temperature variation of free-ranging and captive southern brown bandicoots Isoodon obesulus (Marsupialia: Peramelidae). J. Therm. Biol. 32, 72-77.

Webb, P., 1992. Temperatures of skin, subcutaneous tissue, muscle and core in resting men in cold, comfortable and hot conditions. Eur. J. Appl. Physiol. O 64, 471-476.

Weissenböck, N.M., Weiss, C.M., Schwammer, H.M., Kratochvil, H., 2010. Thermal windows on the body surface of African elephants (Loxodonta africana) studied by infrared thermography. J. Therm. Biol. 35, 182-188.

Wilson, R.P., McMahon, C.R., 2006. Measuring devices on wild animals: what constitutes acceptable practice? Front. Ecol. Environ. 4, 147-154. 
Supplemental Material S1. Characteristics of mantled howling monkey fur, measured from pelts of 18 specimens at the Field Museum of Natural History. Includes $n=13$ females, $n=5$ males, as well as four subspecies of mantled howlers: Alouatta palliata mexicana, $n=4 ; A$. $p$. aequatorialis, $n=10 ;$ A. p. palliata, $n=3 ;$. $p$. coibensis $n=1$.

\begin{tabular}{|c|c|c|c|c|c|c|}
\hline \multirow[b]{2}{*}{ Body region } & \multicolumn{3}{|c|}{ Fur loft length (mm) } & \multicolumn{3}{|c|}{ Total fur length (mm) } \\
\hline & $\bar{x}$ & $\mathrm{SD}$ & Range & $\bar{x}$ & SD & Range \\
\hline \multicolumn{7}{|l|}{ Face } \\
\hline$\overline{\text { Infraorbital fossa }}{ }^{a}$ & 0.86 & 1.29 & $0-4.37$ & 0.95 & 1.37 & $0-4.37$ \\
\hline Supraorbital ridge ${ }^{b}$ & 1.58 & 3.01 & $0-8.97$ & 1.61 & 3.07 & $0-8.97$ \\
\hline Dorsum & & & & & & \\
\hline Between scapulae & 9.27 & 2.76 & $5.26-16.03$ & 24.52 & 3.04 & $19.03-30.60$ \\
\hline $\begin{array}{l}\text { Lumbar region } \\
\text { Ventrum }\end{array}$ & 11.57 & 3.20 & $5.86-16.54$ & 31.47 & 4.15 & $24.63-39.24$ \\
\hline Sternum & 6.93 & 4.72 & $1.39-19.23$ & 32.99 & 11.37 & $4.16-47.64$ \\
\hline Umbilicus & 9.41 & 4.05 & $3.08-16.83$ & 31.37 & 6.20 & $22.81-45.34$ \\
\hline
\end{tabular}

${ }^{\mathrm{a}}$ Of 18 specimens, 11 had no fur in this region.

${ }^{\mathrm{b}}$ Of 18 specimens, 13 had no fur in this region.

Supplemental Material S2. Specifications of the infrared camera used to collect images of mantled howling monkeys.

\begin{tabular}{lc}
\hline Feature & Specification \\
\hline Manufacturer & FLIR \\
Model & E60 bx \\
Infrared resolution & $320 \times 240$ \\
Thermal sensitivity & $<0.045^{\circ} \mathrm{C}$ \\
Accuracy & $\pm 2^{\circ} \mathrm{C}$ \\
Temperature range & $-20^{\circ} \mathrm{C}$ to $120^{\circ} \mathrm{C}$ \\
Frame rate & $60 \mathrm{~Hz}$ \\
Temperature change due to distance & $<0.1$ \\
setting (range: $10 \mathrm{~m}$ ) & \\
\hline
\end{tabular}

